\title{
A Simple Story of a Complex Mind?
}

\section{Polvinen, Merja Kristiina}

Springer International Publishing 2018

Polvinen , M K 2018 , A Simple Story of a Complex Mind? in R Walsh \& S Stepney (eds), Narrating Complexity . Springer International Publishing , Cham , pp. 65-79 . https://doi.org/10.1007/978-3-319-6471

http://hdl.handle.net/10138/322034

https://doi.org/10.1007/978-3-319-64714-2_7

acceptedVersion

Downloaded from Helda, University of Helsinki institutional repository.

This is an electronic reprint of the original article.

This reprint may differ from the original in pagination and typographic detail.

Please cite the original version. 


\title{
A Simple Story of a Complex Mind?
}

\author{
Merja Polvinen
}

Helsinki Collegium for Advanced Studies

Department of Modern Languages, University of Helsinki, Finland

The brain is a complex system, but that doesn't mean it's incomprehensible.

David Eagleman, Incognito (5)

We need a fable again.

Antonio Damasio, The Feeling of What Happens (35)

Among the many complex systems currently being studied, the human brain and the mind it generates are arguably among the most intractable. This chapter of the Narrative Complexity volume introduces the problems of trying to understand the brainmind, ${ }^{1}$ and does it from the perspective of the interdisciplinary field of cognitive humanities. Cognitive humanities aims to bring together the perspectives of the cognitive neurosciences and the humanities without conceding the former priority over the latter, and in a way that preserves the contextualising expertise developed within fields such as history, philosophy and literary and cultural studies. This joint perspective, it is hoped, will afford us a view of the brainmind that does not isolate the biological system from human experience and cultural practice, and that guides our focus to certain conceptual problems associated with the self-reflexive process of trying to understand the system of our brainminds with the kinds of brainminds we have.

At the same time, applying the premises of the humanities on the brainmind may cause more problems than it solves. One of those premises is that the most relevant aspect of thinking is the conscious mind as a generator and manipulator of meanings. Such a view is in contrast with the neurophysiological view of the brain, which takes the causally relevant parts of thought to happen below the level of consciousness - even below the level of experience. This neuropsychological view of what Blakey Vermeule (2015) has called "the new unconscious"-in contrast to the Freudian psychoanalytic tradition-leads the humanities to the edge of what their methodology can reach, precisely because this new unconsious has "no ready-made phenomenology, no language in which to unfold its tales" (Vermeule 2015: 471). Instead of the "endlessly nattering unconscious of psychoanalysis" (471), what the humanities are now dealing with is a split between conscious and nonconscious processes,

\footnotetext{
${ }^{1}$ The term derives from Jaak Panksepp's "BrainMind" (1998/2005: Appendix C), originally introduced as a way of avoiding a mind-body dualism in talking about human cognition and consiousness.
} 
where only the former relatable in terms of narrative. Together with the cognitive sciences the humanities thus encounter the "hard problem", or the explanatory gap between brain states and mental states, and the question whether our scholarship should even try to grapple with properly nonconscious processes. Of course, various forms of art have for centuries tried to represent those processes and their consequences to conscious human experience, but the question remains whether it is at all worthwhile to represent and analyse, from a scholarly humanities perspective, processes that arguably do not enter that experience.

This debate keeps skirting the problems engaged by this volume: the incommensurabilities of systemic organisation and narrative representation. My focus here is, therefore, on a twofold problem: Firstly, the human mind has variously been described both as an emergent feature of the dynamical networks of neuronal activity and as a phenomenon that is inherently dependent on narrative structures. These models seem to do their best work by focusing on, respectively, the low-level neuronal and the high-level cognitive action of the mind, but the connection between them is still difficult to navigate. The second question then becomes whether the irreducibly narrative representational techniques used both by literary works and by the humanities scholarship are able to convey anything about those functions of the brainmind that do not in themselves involve narrativity.

In order to probe these questions, I analyse the rhetorical choices made in two texts that attempt to present - through narrative and without resorting to dynamical systems modelling - the idea of mind emerging from the system of the brain. David M. Eagleman's popular science book Incognito (2011) and Peter Watts's science fiction novel Blindsight (2006) both build on the dynamical systems approach in their understanding of the brainmind. It is also clear that both authors adopt specific narrative strategies in trying to convey to their lay readers the nature of those dynamics. These strategies include such traditional rhetorical tools as analogy and metaphor, as well as, in Eagleman's case, narrativising scientific discoveries into brief stories about the actions and experiences of the scientists involved, or in Watts's case, full-blown fictional — even fantastical—narrative. In addition, both writers take the further step of narrativising the functions of the object they try to talk about - that is, the preconscious mental processes themselves. I will focus on one particular aspect in these texts: their presentation of agency. Which self is the one that selforganises in these narratives? Eagleman offers his readers various levels of the brain and mind as protagonists, and in doing so resorts to narrative means, even as the aim is to convey a sense of the systemic mind. In Watts's novel, narrative agency is given to a character whose sentience and selfhood are questioned by the events of the storyline - and indeed by the 
narrator himself. But in the process of imagining an alternative form of intelligent being for that narrator readers make present for themselves forms of their own, lower-level cognititive processes. Blindsight and the enactive theory of cognition lead me to suggest a possible solution to the question of articulation of the complex system of neural activity to our conscious narrative selves.

\section{Agency, action and the narrative mind}

Talking about agency and action from a complex systems perspective naturally carries some tensions. Agency can be looked at as an epistemic issue that determines whether someone or something is subject to outside forces or is an agent with self-determining force. This deep philosophical issue is, however, shadowed by one of representation: even when the someone or something being represented is known to be without true agency and subject to outside forces, what representational forms are able to convey both temporal activity and lack of agency? Narrativity is traditionally understood to depend on the extent to which events can be presented as cause-and-effect structures, and the lack of linear causal structures in complex systems therefore limits the presence of narrativity. Thus H. Porter Abbott (2008: 233) has argued that the problem the human mind faces in trying to represent complex systems in a narrative form "is not simply the absence of centralized causal control, nor the operation of chance, but the absence of a narratable thread". Emergence, Abbott points out, is a form of action, but because of the "massive distribution of causal agents" typical to complex systems, it is "action without any discernible sequence of events, that is without a story. As such, emergent behavior is by definition unnarratable" (2008: 227, 233).

David M. Eagleman's Incognito: The Secret Lives of the Brain takes a systems view of consciousness as its starting-point, in the sense of presenting the self as an emergent feature of competing coalitions of decision-making networks in the brain. ${ }^{2}$ For Eagleman the self as we experience it is a narrative constructed by those networks, a select pattern that functions to create cohesive directionality to the behaviour of the system as a whole:

[Y]ou are made up of an entire parliament of pieces and parts and subsystems. Beyond a collection of local expert systems, we are collections of overlapping, ceaselessly reinvented mechanisms, a group of competing factions. The conscious mind fabricates stories to explain the sometimes inexplicable dynamics of the subsystems inside the brain. It can be disquieting to consider the extent to which all of

\footnotetext{
${ }^{2}$ Eagleman adds to Marvin Minsky's (1985/1988) thinking the suggestion that rather than there just being a multitude of specialized "subagents" in the brain, those agents are in constant competition with each other for the "single output channel of your behavior" (Eagleman 2011/2012: 107).
} 
our actions are driven by hardwired systems, doing what they do best, while we overlay stories about our choices. (Eagleman 2011/2012: 148)

This overlaying of stories is a way of making the systemic functioning of our own minds accessible to ourselves - an evolutionary quirk that gives us the particular advantage of being able to regulate the competing cognitive subsystems within. Thus the tension between systemic and narrative processes is presented in this text as an inherent part of human cognition. At the same time, in order to to get across its message of brain-internal conflict, Eagleman's text draws on narrative conventions that give agency for the lower-level systems themselves.

The book's opening chapter "There's Someone in My Head but It's Not Me" describes the results of a test measuring male attraction to pictures of female faces. The test showed that men were more attracted to females whose pupils were dilated-a result that did not correlate with the conscious reasons the men gave for their attraction. The choice, Eagleman explains, was not really made by the participants themselves, but by elements of cognition residing below the level of their consciousness. "In the largely inaccessible workings of the brain, something knew that a woman's dilated eyes correlates with sexual excitement and readiness. Their brains knew this, but the men in the study didn't — at least not explicitly" (2011/2012: 5; emphasis original). In such passages, and in line with his subtitle, Eagleman takes the brain and its subagents, rather than the self, to be the main protagonist of his book, and, accordingly, extended parts of the text present the brain as the agent of action. Where Daniel Dennett wrote back in 1978 that the metaphor of subsystems as active "homunculi" will fade quickly and be replaced by more accurate forms of description (1978/1981: 124), Eagleman still finds it necessary in 2011 to speak of "experts", "factions", "rivals" and "allies" to make his point (2011/2012: 107-109).

The same extension of agency also takes place when Eagleman creates an analogy between consciousness and the headlines of a national newspaper to suggest the superficiality of our awareness when it is compared to the deep layers of action conducted by the competing processes within the brain:

Your brain buzzes with activity round the clock, and, just like the nation, almost everything transpires locally: small groups are constantly making decisions and sending out messages to other groups. [...] By the time you read a mental headline, the important action has already transpired, the deals are done. (Eagleman 2011/2012: 6)

And not only is the populace acting beyond the knowledge and control of the reader of headlines, that reader has lost awareness of the fact that the events occur without its influcence: 
However, you are an odd kind of newspaper reader, reading the headline and taking credit for the idea as though you thought of it first. You gleefully say, 'I just thought of something!', when in fact your brain has performed an enormous amount of work before your moment of genius struck. [...] And who can blame you for thinking you deserve the credit? The brain works its machinations in secret, conjuring ideas like tremendous magic. It does not allow its colossal operating system to be probed by conscious cognition. The brain runs its show incognito. (Eagleman 2011/2012: 7)

This disjunction between conscious, singular agency and the non-conscious, proliferating processes in Eagleman's presentation evokes the division between system and narrative, but does so in a way that assigns agency to the systemic processes. ${ }^{3}$ Eagleman has thus chosen narrativity over accuracy in this book, and even as he wants to present to his readers a mind that is subject to the determining forces of the systemic interactions of the brain (as opposed to a self-determining subject), the demands of narrative structuring force him to (inaccurately) transfer the idea of intentional agency to another level in the process.

One way out of the representational impasse that has been suggested is the narrative view of the mind itself. This recursive solution suggests that rather than there being an explanatory gap between mental function and its narrative representations, our minds themselves are narrative in form, even though their neural underpinnings may be systemic. Jerome Bruner, in the 1990 volume Acts of Meaning, sets out to offer an alternative to the long-standing computational view of the mind. Whereas the computational model focuses on analysing human behaviour as the result of input, linear processing and output, Bruner's form of "cultural psychology" focuses on understanding consciousness through the concepts of action and agency. "A cultural psychology, almost by definition, will not be preoccupied with 'behavior' but with 'action', its intentionally based counterpart," Bruner notes. Furthermore, because Bruner focuses on "situated action - action situated in cultural settings, and in the mutually interacting intentional states of the participants" (Bruner 1990: 19; emphasis original), it is also central to his view that the action becomes what it is not only because of the intention of a single individual, but also because that individual's intention is part of a larger network of cultural information. Thus, in order to act meaningfully and intentionally,

\footnotetext{
${ }^{3}$ Eagleman also uses the second person pronoun as a central character in Incognito. In this he follows an established convention of popular psychology and self-help books, and the fluctuation between "you" and "the brain" or even "your brain" forms a rhythm which moves in accordance with whether Eagleman is discussing neural functions or the level of human experience. There is one further protagonist — "we" — which appears when Eagleman's discussion of human behaviour moves to failures of cognition (e.g. visual illusions on p. 18). Presumably the change occurs to avoid the implication that specific readers alone, and not humanity in general (or even Eagleman himself) fail in such a way: consider the rhetorical effect of "Why do you fail to perceive these obvious things? Are you really such a poor observer of your own experiences?" in comparison with the "we" used in the original on p. 21.
} 
human beings make use of "folk psychology" — a pool of knowledge about human experience and action that is used not only to understand the actions of others, but also to make sense of our own experiences and guide our own future actions. "Folk psychology," Bruner (1990: 4243) writers, "is about human agents doing things on the basis of their beliefs and desires, striving for goals, meeting obstacles which they best or which best them, all of this extended over time." Crucially, the organising principle of this pool of knowledge is "narrative in nature", not "logical or categorical" (Bruner 1990: 42).

Nearly twenty years later, Bruner's idea of folk psychology is being developed further by scholars combining his psychological and philosophical perspective with cognitive neuroscience. Daniel D. Hutto (2009; Hutto and Myin 2013), for example, takes up the idea of folk psychological narratives and argues that not only are they a crucial souce of information for understanding ourselves and others, but also that our understanding of human beings and our understanding of narratives develop in a mutually dependent fashion. Folk psychology, Hutto suggests, "is essentially a narrative practice - its exercise, always and everywhere, invokes our capacity to construct or digest narratives of a special sort [...] that make explicit mention of how mental states (most prominently, beliefs and desires) figure in their lives" (Hutto 2009: 11).

It must be noted, however, that neither Bruner nor Hutto claims a narrative structure for raw perception so much as "a readiness or predisposition to organize experience into a narrative form, into plot structures and the rest" (Bruner 1990: 45). Also, rather than the details of neuropsychology, Bruner is interested in the high-level operations of human minds as they negotiate interpersonal relationships and cultural contexts. Roger C. Schank's Tell Me a Story: Narrative and Intelligence, originally published for an AI audience the same year as Bruner's Acts of Meaning, also uses an argument about the role of story as a way of organising information vital to the human being, but where Bruner sees human beings as users of the narratives of folk psychology, Schank leans towards locating agency in the narratives themselves. Human intelligence — and any artificial intelligence that would emulate it-Schank argues, consists of the application of narratives of what we have already experienced (or narratives of others' experiences) to a new situation. Such information is coded in our memories in the form of "scripts", or sets of "expectations about what will happen next in a well-understood situation" (Schank 1990/1995: 7), and these scripts are "indexed" in such a manner as to be readily available in new but similar situations (Schank 1990/1995: 10-11). Schank's background in AI leads him to imply that human narrative intelligence is only an application of these pre-learned (or programmed) scripts, which are 
stored and retrieved in the brain in a way analogous to a computer. In Schank's argument, therefore, conscious intention concedes much of its agency to the stored scripts, and taken in its strong form, his hypothesis suggests that "scripts obviate the need to think" (Shanck 1990/1995: 8).

Arguably the most far-reaching argument about the narrative roots of human selves has been made by Daniel Dennett, who suggests that the practice of storytelling is so central to our social interaction and intelligence that it could be said to define our evolutionary niche: "Our fundamental tactic of self-protection, self-control, and self-definition is not spinning webs or building dams, but telling stories" (Dennett 1991/1993: 418). In Dennett's idea of storytelling humans, agency is again given mainly to the narratives themselves, even as they and the self form a feedback loop: "Our tales are spun, but for the most part we don't spin them: they spin us. Our human consciousness, and our narrative selfhood, is their product, not their source" (Dennett 1991/1993: 417-418). This self Dennett calls the "centre of narrative gravity", a metaphor which draws on an analogy with physicists' positing of a centre of gravity for an object, such as a chair. While that centre can be talked about as if were an object, it is "a theorist's fiction" (Dennett 1992: 103):

The physicist does an interpretation, if you like, of the chair and its behavior, and comes up with the theoretical abstraction of a center of gravity, which is then very useful in characterizing the behaviour of the chair in the future, under a wide variety of conditions. (Dennett 1992: 105; emphasis original)

Thus Dennett's formulation of the self is of a postulated unified agent which, in fact, only comes to be in the process of telling stories about itself, and although it can be talked about as an entity, it does not exist beyond the discourse that generated it. ${ }^{4}$

If Bruner, Schank and Dennett all have searched for ways in which our mental lives are dependent on narrative, none of them has a background in the study of narrative per se. On the side of literary studies and narratology, David Herman's work builds on Bruner's, and develops it towards a more analytical examination of the structures involved. Herman understands the intersection of narrative theory and "the sciences of mind" to cover two interrelated questions:

How do stories across media interlock with interpreters' mental capacities and dispositions, thus giving rise to narrative experiences? and How (to what extent, in

\footnotetext{
${ }^{4}$ Dennett's version of the narrative self has engaged the imaginations of many literary authors, such as the American novelist John Barth, who finds the idea to be in perfect concert with his own abiding fascination with the figure of Scheherazade - a character who told herself into life and who is, for Barth, "the (fictionalistical, asifish) scenario-spinner that is the continuously auto-creating self of every one of us" (Barth 1992/1995: 196; emphasis original; see also Polvinen 2008: 141-186). For arguments against the idea of a narrative self, see Strawson (2004).
} 
what specific ways) does narrative scaffold efforts to make sense of experience itself? (Herman 2013a: 421)

Herman is thus focused on analysing the structures of stories as "models of action" (2009: 40), both in the sense of learned action-structures having narrative form, and in the sense of stories coding within themselves various action-structures that can then be examined-both for the better comprehension of the nature of human action and of the nature of narrative. Stories, Herman suggests, are cognitive tools in the Vygotskian sense: they are "a primary technology for making sense of how things unfold in time [...], one that helps reveal how actions arise, how they are interrelated, and how much salience they should be assigned within a given environment for acting and interacting" (Herman 2013a: 431). As with Bruner, Herman's focus remains on the higher levels of cognition, and he explicitly steps away from claiming a role for narrative sensemaking on the nonconscious level (2013b: 73).

The paradigm of the narrative self thus argues that narrative can be an accurate form of representation for mind and consciousness, since those phenomena are themselves narrative processes. At the same time, however, it does not fully take on the hard problem of the gap between conscious experience and the systemic neural level.

\section{Mind as a complex system}

The roots of the dynamical systems approaches to cognition lie in the cybernetic revolution of the 1940s and 50s, in the work of McCullough, of Shannon and Weaver, and of von Neumann (Port \& van Gelder 1995b; 36), as well as in the more "organismic" theories of biological systems in the 1960s and 70s (Thelen \& Smith 1995: xix). An initial split between two approaches - one focusing on computational models and another gravitating towards neural netwoks - eventually led to the latter developing in the 1980s into connectionism, and further into dynamical systems approaches (Port \& van Gelder 1995b: 36-39). Today, the view that at least at the neuronal level the best form of description for the brainmind is a dynamical one is widely shared, and the central metaphor of mind as a computer has been overtaken by that of mind as a living, interacting system.

The central tenets of the dynamical systems view of mind and brain are:

The cognitive system is not a computer, it is a dynamical system. It is not the brain, inner and encapsulated; rather, it is the whole system comprised of nervous system, body, and environment. The cognitive system is not a discrete sequential manipulator of static representational structure; rather it is a structure of mutually and simultaneously influencing change. Its processes do not take place in the arbitrary, discrete time of computer steps; rather, they unfold in the real time of ongoing change 
in the environment, the body, and the nervous system. The cognitive system does not interact with other aspects of the world by passing messages or commands; rather, it continuously coevolves with them. (Port \& van Gelder 1995b: 3; emphases original)

The study of the brainmind from the perspective of dynamical systems theory has, accordingly, moved from symbol-based models and computational logic to studying rates of change and phase-space trajectories that are seen to correspond to some observable behaviours. For example, the methods used by the scholars published in Port and van Gelder's 1995 volume Mind as Motion: Explorations in the Dynamics of Cognition include both quantitative and qualitative modeling, as well as systems-theoretically informed description of the cognitive systems under study. With these tools the chapters examine issues such as language processing, the binding problem and the early childhood development of embodied cognition. ${ }^{5}$

If the dynamical view may now be said to be accepted as a description of interactions on the neuronal level, it is also possible to take it as a way of undermining the need for different approaches for lower-level and higher-level processes. Whereas the dominant model of computational cognitivism took cognition to consist of two different processesunconscious symbolic computation on the one hand, and conscious experience on the otherthe dynamical view takes that distinction to be "a contemporary remnant of the traditional philosophical view that mind is somehow fundamentally distinct in nature from the material world (the body and the external physical world)" (Port \& van Gelder 1995a: viii). Thus, "if we are interested in cognitive systems, then the behaviors of interest are their cognitive performances (perceiving, remembering, conversing, etc.), and it is these behaviors, at their characteristic time scales, that must unfold in a way described by the rule of [mathematical] evolution" (Port \& van Gelder 1995b: 11; emphasis original). Similarly, Esther Thelen and Linda B. Smith suggest that dynamical systems theory can break down the barrier between ways of understanding the lower-order processes of brain organisation on the one hand, and the higher-order processes of complex perception and cognition on the other. Abstract reasoning and metacognition, they argue, "are in principle no different from the less-abstract mental operations upon which they are ontogenetically based, and that, indeed, a common dynamic must unify all brain function as well as changes in brain and behavior" (Thelen \& Smith 1994: 312).

However, Thelen and Smith also note the danger of thinking that just because the

\footnotetext{
${ }^{5}$ Emotions have become much more central for the cognitive sciences since the 1990s, and emotional episodes have also been seen in terms of dynamical patterns (see Colombetti 2014: 53-82).
} 
dynamics of the behaviour remains the same across various levels of cognition, the processes themselves repeat from one level to the next. An act such as that of weaving a fabric, and the act of thinking about weaving are different, Thelen and Smith insist, and should not be expected to be the same patterns of activity:

Thinking, like weaving, is a behavior, a product of the entire system's activity. However, the patterns of activity that are weaving and the patterns of activity that are thinking about weaving are not the same nor is one in any way contained within the other or 'raised up' to form the other. (Thelen \& Smith 1994: 337)

Also, and in accordance with the dynamical systems theory more generally, this model of mind separates the idea of "activity" from the idea of "action"- from intention and agencyand thus gives it a very different role than the narrative paradigm does. The presence of agency and intentionality in representations of dynamical systems, therefore, tends to give them a false sense of teleology — but at the same time our understanding of those systems depends on our ability to represent them in ways that make sense to us. So even if the dynamical systems view of the brain shows us all cognitive performance in terms of the same dynamics, the question remains how a narrative representation could articulate the agentless behaviour of our nonconscious level.

\section{Enacting complexity}

Peter Watts's science fiction novel Blindsight (2006), presents the problem of lower and higher-level processing in much the same way as Eagleman in his popular science book. The novel takes the form of a classic first-contact story: an expedition of specialists is sent into deep space to intercept an alien vessel that has sent a group of probes to Earth. Among the technicians, military experts and linguists, the expedition includes the novel's narrator, Siri Keeton, a "Synthesist" or official observer. Due to severe epilepsy he suffered as a child, Siri has had half of his brain removed and replaced with an extensive computer databank and processor, making him uniquely able to analyse massive amounts of data for their large-scale patterns. At the same time, however, he has lost the ability to intuitively reflect on the relationship between himself and his environment, and is forced to rely on learned algorithms to interpret the actions and intentions of those around him. While his computer-assisted mind is able to analyse incredible masses of data on the surface behaviour of both the alien creatures and the people around him, as well as creating solutions on the basis of that data, Keeton is initially unable to properly access those levels of his own intelligence, which makes his sense of self muted and fragmented. 
Keeton's mirror image in the novel is the alien the team encounters: a form of life that is massively intelligent but without sentience. Without a conscious self, the alien creatures, or "scramblers," embody the idea of multiple brain processes that do the actual work of cognising before consciousness has even an inkling of a decision needing to be made. "Imagine you're a scrambler", Keeton exhorts both himself and the novel's readers, in an attempt to understand what the team is facing. "Imagine you have intellect but no insight, agendas but no awareness. Your circuitry hums with strategies for survival and persistence, flexible, intelligent, even technological-but no other circuitry monitors it. You can think of anything, yet are conscious of nothing" (Watts 2006: 323; emphasis original). The novel's storyline develops steadily towards the predictable disaster, with Keeton the only survivor, and it does so by weaving together Keeton's voice and personality with the slow revelation of the scramblers' strange form of cognition. Yet, at the same time as readers' understanding of the nature of the scramblers' intelligence grows, Keeton himself develops in the opposite direction by gaining an intuitive connection to the processes of his modified brain. Initially, reflective awareness appears in his experience as moments of the blindsight the novel's title refers to: as fleeting visualisations in the corner of his eye that result from one part of his brain attempting to tell his conscious mind something by "passing notes under the table" (Watts 2006: 319). By the end, Keeton's intuitive connection to his own subroutines is restored, making him able to tell the narrative he tells - a narrative that is much more than the surface data of the events he witnessed. "And now the game is over, and a single pawn stands on that scorched board and its face is human after all" (Watts 2006: 360).

What makes Watts's novel particularly interesting in comparison to Eagleman's popular-science depiction is its choice of narrator and the consequent imaginative actions readers are asked to perform. Time and again Keeton slips into second-person narration to command himself to imagine being something else - either the alien creatures or one of the crewmembers. For Keeton, the command to imagine is a way of bootsrapping himself towards human sentience, of creating the reflective layer that intelligence needs in order to become aware of both its own processes and of the thoughts and intentions of other beings. The same command, however, also applies to the novel's readers, who, by actively imagining the characters and events of the fiction, exercise their own sentience: "Imagine you are Siri Keeton," begins the novel proper. At its end, the now fully cognitively human narrator reminds his audience that even in his restored state, they cannot just take his word as proof of sentience, but that like the Chinese room, he might just be "faking it", and that the readers" only access to his sentience is through empathetic imagination. "So, I can't really tell you, 
one way or the other. You'll just have to imagine you're Siri Keeton" (Watts 2006: 21, 362).

Blindsight creates an opportunity for readers to go through a cognitive process not otherwise available to them, and in this it partakes in one of the shared roles of all fictional narratives. What is unusual about it, I suggest, is its attempt to use the general toolbox of fiction to give its readers access to levels of nonconscious cognitive processing - to activate what Richard Walsh in Chapter 5 calls our "sense of wonder" of the systemic interactions that we otherwise find difficult to make sense of. Thus, while the narrative and dynamical systems models of the mind may both have their separate roles to play in our descriptions of the lower and higher levels of mental action, I also wish to examine the ways in which narrative might help the mind to make its own systemic elements present for the reflective, narrative consciousness. Is it possible for narrative representation to engage the mind in systemic thinking - that is, is it possible for readers of Eagleman or Watts to gain a sense of the complex system of their own brains while having it represented to them in a narrative form, rather than through the system-based forms of thought made possible by mathematics, visual illustrations?

One description of how such a process might be possible is the theory of enactive cognition, which inherited the willingness shown in the 1990s in the works of Port \& van Gelder and Thelen \& Smith to engage dynamical systems theory and methods in the study of the higher levels of cognitive functioning. Francisco Varela and Evan Thompson, in particular, have been on the forefront of fashioning a model of enactive cognition on the basis of autopoiesis, connecting the physical properties of living beings with the organisational properties of life as well as those of mental processing. In this view, cognition is understood to mean simply all the activities of a biological system that can be defined as information processing, including the organismic regulation of the body and the sensorimotor coupling between the organism and its environment. In this sense, all life could be defined as cognition of some sort or another. The kind of cognition that humans practice-including intersubjective interaction and recognition of intentional action-is seen as an extension of, rather than a departure from, this basic kind of information exchange between an organism and its environment (e.g.Varela, Thompson and Rosch 1991/1993).

The three main points of enactive cognitive science have been formulated by Thompson and Varela (2001: 418) as follows:

(1) [U]nderstanding the complex interplay of brain, body, and world requires the tools and methods of nonlinear dynamical systems theory;

(2) traditional notions of representation and computation are inadequate;

(3) traditional decompositions of the cognitive system into inner functional 
subsystems or modules ("boxology") are misleading, and blind us to arguably better decompositions into dynamical systems that cut across the brain-body-world divisions.

Enactive cognition thus conceptualises the organisation of mind very differently from the traditional computational models, where the emphasis is on the interaction of processing units within the brain. Here the focus is on how large-scale brain activity emerges out of the transient integration of neural events, as well as on how the sensorimotor coupling of the embodied mind with its environment has to be understood as a feedback loop. So even if the idea of autopoiesis roots enaction in the very lowest levels of cognition, the enactive approach also aims to understand higer-level cognitive processing, as well as offer an explanation of the join between the two. This is because the autopoietic feedback loops between the organism and its environment also involve the concept of the enacting agent. As argued by Di Paolo, Rhode and De Jaegher in a seminal collection of essays on enaction (2010: 39), "[a]utonomous agency goes even further than the recognition of ongoing sensorimotor couplings as dynamical and emphasizes the role of the agent in the constructing, organizing, maintaining, and regulating those closed sensorimotor loops". In doing so, a cognitive agent enacts a world for itself, even as its own being is determined by that world. Thus agency and the environment are tied together in a process that generates not only the agency itself (as a living, cognising being) but also the environment in which that agent operates. In the case of Watts narrative, we enter a similar feedback relationship: one where the fiction as a cognitive environment is constituted by our mental actions, but also where that environment changes - both by limiting and by extending - the actions we can make.

Enactive cognitive science has not so far given much attention to narrative. Enaction is an approach mostly used in the study of sensory perception and sense-making, and even though it has recently been applied to the development of symbolic action in e.g. makebelieve, this tends to be done in a way that ignores extended temporality. ${ }^{6}$ However, the central role of narrative in human imagination makes it natural to seek for further purchase between enactive cognition and narrative, and to elaborate the role of different forms of action in the enactive sense-making. What makes the enactive view relevant for the discussion on narrative and complexity in particular is, therefore, not only the way it connects

\footnotetext{
${ }^{6}$ Thus, when Di Paolo, Rhode and De Jaegher (2010: 78) speak of a child imagining a spoon to be a car, they focus on the embodied action of the play, rather than on the possibility of a storytelling frame for the action: "When a child skillfully supplements the perceptual lack of similarity between a spoon and a car by making the spoon move and sound like a car, he or she has grasped in an embodied manner the extent to which perception can be action-mediated. With his or her body, the child can now alter sense-making activity, both on external objects, as well as his or her own actions and those of others."
} 
these processes of autopoiesis all the way up to the level of conscious thought, but also the fact that enactment offers a way of conceptualising a form of conscious, narrative access to our own systemic minds. Despite the fact that narrative descriptions may lose the specifically systemic characteristics of the complex system they try to depict, the enactive perspective suggests that through the process of participating in the sense-making encoded in a narrative we might still be able to gain access to those characteristics, and to inhabit what Richard Walsh calls "the edge of sense". Thus the mind might be able to constitute for itself-in the phenomenological sense of bringing to awareness-its own systemic functioning in the enaction of a narrative representation, rather than the systemic functioning being replicated in the representation as such.

\section{Conclusion}

It would be very premature to claim that the problem of representing complexity in narrative is solved by the arrival of the theory of enactive cognition, and the research into the interplay of narrativity and complex systems is only beginning. What enactive cognition does point us towards is the need to examine more carefully the uses of various structural, metaphorical and narrativising techniques within popular science and other texts attempting to convey the idea of complexity to a non-specialist audience. This kind of research might be able to find new ways to discuss the rhetorical effects of such writing, as well as extend our existing understanding of the effects of narrative engagement with the help of the enactive paradigm. If the problem of narrative models of complexity not sharing the specifically systemic elements seems inescapable, perhaps mapping the thing represented and its representation on each other is, indeed, the wrong way to look at the problem at hand. Instead, the enactive view offers us a way of looking at what kind of a combination of narrativity and metaphoric or symbolic representation is capable of triggering the imagining of complex systems in our minds.

As Marco Bernini also suggests in this volume, even if the neural correlates of mental states cannot as such be accessed by the conscious mind, there is an argument to be made for seeing the enactment of a narrative as a method for the mind to explore not only its own narrative intuitions but also the systemic level of its functioning. The two descriptions of human cognition discussed in this chapter both attempt to make the systemic nature of the brainmind available to our human, narratively inclined form of cognition, and I am intuitively drawn towards the idea that the more complex and extended narrative enaction engaged by 
Watts's novel results in fuller sense-making than Eagleman's combination of description, argumentation and brief parables. In her essay "Making the Cut", N. Katherine Hayles (2000: $145,160)$ has argued that narrative is the necessary counter to systems theory precisely because it has the "loose bagginess" envisioned by Henry James - because it is "contextual" and "polysemous" and able to go beyond "the closures that systems theory would perform". In contrast with the the minimalist, narratively confounding works that Bernini analyses, in this case it might be exactly the loose bagginess of extended narrative and fictional excess that allows for the fuller enactment. It thus seems that both minimalism and excess may achieve the desired result in different contexts.

On the other hand, it is true that narrative fiction in general steps into an area where it is difficult if not impossible to maintain many of the aspects of good science writing (such as the separation of fact and invention). It is an area where the needs of a good story may override the needs of accurate science, and where readers' attitudes toward the information offered is being directed by the rules of fictionality. Thus I would not suggest that popular science representations should abandon their own conventions and replace them with those of science fictional narratives; just that the benefits that come with enactive cognition may depend on the mixture of narrative and fictionality that is more easily available to novels than to science writing. However, we are only just beginning to understand the potential of the enactive frame for the analysis of narrative representation, and encountering such variety in the phenomena it reveals - as well as contextually variable and even mutually contradictory effects of the representational techniques involved - should not cause undue surprise.

\section{Works Cited}

Abbott, H. Porter. 2008. "Narrative and Emergent Behaviour." Poetics Today 29.2: 227-244.

Barth, John. 1992/1995. “Once Upon a Time: Storytelling Explained.” Further Fridays: Essays, Lectures, and Other Nonfiction 1984-94. Boston et al.: Little, Brown. 181-196.

Bruner, Jerome. 1990. Acts of Meaning. Cambridge, MA and London: Harvard University Press.

Colombetti, Giovanna. 2014. The Feeling Body: Affective Science Meets the Enactive Mind. Cambridge, MA and London: MIT Press.

Damasio, Antonio. 2010/2012. Self Comes to Mind: Constructing the Conscious Brain. New York: Vintage. 
Dennett, Daniel C. 1978/1981. Brainstorms: Philosophical Essays on Mind and Psychology. Cambridge, MA and London: MIT Press.

1991/1993. Consciousness Explained. London et al.: Penguin.

1992. "The Self as the Centre of Narrative Gravity." In Frank S. Kessel, Pamela

M. Cole and Dale L. Johnson (eds.), Self and Consciousness: Multiple Perspectives.

Hillsdale, NJ: Lawrence Erlbaum. 103-115.

Di Paolo, Ezequiel A., Marieke Rhode and Hanne De Jaegher. 2010. "Horizons for the Enactive Mind: Values, Social Interaction, and Play." In John Stewart, Olivier Gapenne and Ezequiel A. Di Paolo (eds.), Enaction: Toward a New Paradigm for Cognitive Science. Bradford. Cambridge, MA and London: MIT Press. 33-87.

Eagleman, David M. 2011/2012. Incognito: The Secret Lives of the Brain. New York: Vintage.

Hayles, N. Katherine. 2000. "Making the Cut: The Interplay of Narrative and System, or What Systems Theory Can’t See.” In Willam Rasch \& Cary Wolfe (eds.), Observing Complexity: Systems Theory and Postmodernity. Minneapolis: University of Minnesota Press. 137-162.

Herman, David. 2009. "Storied Minds: Narrative Scaffolding for Folk Psychology." Journal of Consciousness Studies 16.6-8: 40-68.

- 2013a. "Narrative Theory and the Sciences of Mind." Literature Compass 10.5: 421-436.

- 2013b. Storytelling and the Sciences of Mind. Cambridge, MA and London: MIT Press.

Hutto, Daniel D. 2009. "Folk Psychology as Narrative Practice." Journal of Consciousness Studies 16.6-8: 9-39.

Hutto, Daniel D. and Erik Myin. 2013. Radicalizing Enactivism: Basic Minds without Content. Cambridge, MA and London: MIT Press.

Minsky, Marvin. 1985/1988. Society of Mind. New York et al.: Simon \& Schuster.

Panksepp, Jaak. 1998/2005. Affective Neuroscience. Oxford et al.: Oxford University Press.

Polvinen, Merja. 2008. Reading the Texture of Reality: Chaos Theory, Literature and the Humanist Perspective. English Department Studies 6. Helsinki: University of Helsinki.

Port, Robert F. and Timothy van Gelder. 1995a. "Preface." In Port and Van Gelder (eds.), Mind as Motion: Explorations in the Dynamics of Cognition. Cambridge, MA and London: MIT Press. vii-X. 1995b. "It's About Time: An Overview of the Dynamical Approach to Cognition." 
In Port and Van Gelder (eds.), Mind as Motion: Explorations in the Dynamics of Cognition. Cambridge, MA and London: MIT Press. 1-44.

Schank, Roger C. 1990/1995. Tell Me a Story: Narrative and Intelligence. Rethinking Theory. Evanston: Northwestern University Press.

Stewart, John, Olivier Gapenne and Ezequiel A. Di Paolo. 2010. "Introduction.” In John Stewart, Olivier Gapenne and Ezequiel A. Di Paolo (eds.), Enaction: Toward a New Paradigm for Cognitive Science. Bradford. Cambridge, MA and London: MIT Press. vii-xvii.

Strawson, Galen. 2004. “Against Narrativity.” Ratio XVII: 428-452.

Thelen, Esther \& Linda B. Smith. 1994. A Dynamic Systems Approach to the Development of Cognition and Action. Bradford. Cambridge, MA and London: MIT Press.

Thompson, Evan and Francisco J. Varela. 2001. "Radical Embodiment: Neural Dynamics and Consciousness." Trends in Cognitive Sciences 5.10: 418-425.

Varela, Francisco J., Evan Thompson and Eleanor Rosch. 1991/1993. The Embodied Mind: Cognitive Science and Human Experience. Cambridge, MA and London: MIT Press.

Vermeule, Blakey. 2015. "The New Unconscious: A Literary Guided Tour." In Lisa Zunshine (ed.), The Oxford Handbook of Cognitive Literary Studies. Oxford et al.: Oxford University Press. 463-482.

Watts, Peter. 2006. Blindsight. New York: Tor.

\section{Discussion and comment (on earlier draft)}

MB on: Together with the cognitive sciences the humanities thus encounter the "hard problem", or the explanatory gap between brain states and mental states, and the question whether our scholarship should even try to grapple with precognitive processes.

I see what you are aiming at, and it is a very important point (i.e., "how can literature have something to say on what happens only at the brain level?") and it is an aspect underlying also my essay in this volume. However, I am not sure that Kahnemann's distinction is the kind of distinction you need or are referring to. It seems to me you are pointing at a distinction of level (mental vs. neuronal events) whereas $\mathrm{K}$ is pointing at a distinction of agency or conscious experience of an action (thinking, moving, perceiving). Literature can easily represent what is beyond the threshold of agency or consciousness (showing non-attentional moments of a character that is about to get hurt by a bus, for instance) but might have some serious problem in representing what happens in the brain at that moment, or am I getting something wrong?

MP: I dropped Kahnemann - it was a bit of a last-minute addition to the previous version anyway. But my point here was not so much to talk about what literature can do, but 
about what literary studies can do in terms of analysing the patterns of experience that are represented in texts, but also recreated by readers.

SS on: Emergence, Abbott points out, is a form of action, but because of the "massive distribution of causal agents" typical to complex systems, it is "action without any discernible sequence of events, that is without a story. As such, emergent behavior is by definition unnarratable" (2008: 227, 233).

interesting perspective. Richard and I originally started discussing that what made a particular complex system behaviour *emergent* was that it *was* narratable -- we "notice" it, conceptualise it, because we can narrate it -- eg flocking is narratable, surely?

MP: I think what Abbott means is that e.g. flocking is describable, but only narratable in the sense of it being a phenomenon that can be observed and the observation could then be narrated. But it is not narratable in the sense that the cause-and-effect relations within that behaviour could be put in a narrative form (imagine trying to tell the story of bird A turning left and then bird B and then... doesn't work).

SS on: An act such as that of weaving a fabric, and the act of thinking about weaving are different, Thelen and Smith insist, and should not be expected to be the same patterns of activity.

the physical body movements are different, but many of the mental processes are the same (mirror neurons etc), so it isn't simply a category difference

MP: The idea of mirror neurons has come along after the dynamical view, and I admit I don't know whether it has been incorporated in some sense. But on the other hand, the idea of mirror neurons itself (as well as mental representations in general) has received a lot of criticism, and the point here is to draw attention to the differences between the dynamics and the behaviour on the one hand, and activity and intentional action on the other.

SS on: In this view, cognition is understood to mean simply all the activities of a biological system that can be defined as information processing, including the organismic regulation of the body and the sensorimotor coupling between the organism and its environment.

that's a rather peculiar weak of "cognition", literally making it synonymous with info procesing. I think I prefer Irun Cohen's defn:

a cognitive system is one that has three properties:

* it contains internal images of its environment

* it self-organises by updating its internal images based on its experience

* it makes decisions based on its internal state

Crucially -- because decisions are based on internal state that reflects the env -- if the env/state changes, the decisions can change (it can *learn*)

MP: The point of enactive cognition is to move towards seeing cognition as interaction with environment without brain-internal representations. But rather than have the full debate here, I just brought some of these points out more towards the beginning of the chapter 
to guide readers' expectations better.

MB on: The kind of cognition that humans practice-including intersubjective interaction and recognition of intentional action - is seen as an extension of, rather than a departure from, this basic kind of information exchange between an organism and its environment (e.g.Varela, Thompson and Rosch 1991/1993).

Since this is the kind of bridge/path linking complex neuronal interaction with their mental counterpart you are (rightly) looking for to support your argument, I would spend a couple of more lines around the nature of this fractal hypothesis of enactivism, where small-scale and large-scale cognition are unified under the same principles.

MP: Agreed - have tried to bring this up more in the current version.

SS on: The two descriptions of human cognition discussed in this chapter both attempt to make the systemic nature of the brainmind available to our human, narratively inclined form of cognition, and I am intuitively drawn towards the idea that the more complex and extended narrative enaction engaged by Watts's novel results in fuller sensemaking than Eagleman's combination of description, argumentation and brief parables.

I've read Blindsight. Yet I missed quite a lot of what you talk about here. So it was not more sense-making for me!

MP: On the other hand, literary works are rarely meant to be one-off "downloads" of information into their readers minds, but instead this kind of 'fuller' sense-making often comes out only after repeated readings. And not necessarily to every reader - half of this comes from my particular brainmind having done certain kind of work with the stuff offered to me by the matrix of the text. 